\title{
América Latina: da construção do nome à consolidação da ideia
}

\author{
Rafael Leporace Farret e Simone Rodrigues Pinto
}

\section{RESUMO}

O objetivo do presente artigo é examinar o processo de construção da ideia de América Latina, ou seja, o surgimento do conceito e sua simbologia na perspectiva da modernidade. $\mathrm{O}$ recorte cronológico compreende do período colonial até a conjuntura de consolidação do termo América Latina, em fins do século XIX. Discute-se a criação do nome - América Latina - e sua predominância frente aos demais termos empregados para definir uma identidade continental, tais como hispanoamérica, indoamérica, iberoamérica, entre outros, a partir da perspectiva analítica do filósofo uruguaio Arturo Ardao, sem deixar, entretanto, de cotejá-la com trabalhos de outros especialistas.

Palavras-chave: América Latina, identidade, debate historiográfico.

\begin{abstract}
The purpose of this paper is to examine the process of building the idea of Latin America, that is, the emergence of the concept and its symbolism in the perspective of modernity. The chronology includes from the colonial period to the context of consolidation of the term Latin America in the late nineteenth century. It discusses the creation of the name - Latin America - and its prevalence compared to other terms used to define a continental identity, such as Hispanoamerica, Indoamerica, Ibero-America, among others, from the Uruguayan philosopher Arturo Ardao awnalytical perspective, while, however, collating it with work of other experts.
\end{abstract}

Keywords: Latin America, identity, historiographical debate. 


\section{Introdução}

Precisamos separar as palavras das coisas, como diz Walter Mignolo ${ }^{1}$. Neste sentido, o objetivo do presente artigo é apresentar historicamente como se deu o processo de construção da ideia de América Latina, não a entidade em concreto, mas o nascimento do nome e sua simbologia na perspectiva da modernidade.

O "descobrimento" da América teve um impacto não somente no cenário social e econômico europeu, mas principalmente revolucionou o imaginário moderno sobre as extensões além-mar. Qual deveria ser o nome desse continente tão diverso? A história da construção da denominação dessa vasta faixa de terra coincide com a história das tentativas de apropriação desse imaginário - e conseqüentemente das riquezas materiais que o acompanhavam. Primeiro os ibéricos, depois os franceses, mais tarde os "norte-americanos". A construção do nome deixou na penumbra e no esquecimento qualquer tentativa de valorizar os povos autóctones, indígenas ou negros. Sempre da perspectiva europeia, a América Latina foi se estabelecendo no mundo ocidental moderno como periferia, inferiorizada e explorada. Compreender o processo de construção do nome compóe um esforço maior de entender nossa situação colonial, de questionar nossa identidade, a fim de buscar superar nosso complexo de Caliban².

Nosso recorte cronológico vai do período colonial até o momento de consolidaçáo do termo América Latina, em fins do século XIX. Deixando de lado o complexo debate da existência ou não de uma única identidade latino-americana, o que propomos aqui é determinar quais os passos e motivos que levaram a população dessa parte das Américas a aceitar uma ideia de América Latina. Para isso, concordamos com a afirmação de Miguel Rojas Mix, de que a história da identidade latino-americana é também a "história dos diversos nomes da América e das razóes pelas quais estes nomes foram impostos"3. Assim, procuraremos discutir a criação do próprio nome América Latina e a explicação do porquê de sua vitória em relação aos demais termos existentes na região utilizados para definir sua identidade, tais como hispanoamérica, indoamérica, iberoamérica etc.

Antes de examinarmos o avanço dos estudos acerca deste assunto, devemos saber de antemáo quão elevados são os seus níveis de dificuldade. A começar pela própria imprecisão do conceito de América Latina, visto que é muito difícil determinar quais países compóem-na, ou quais os critérios utilizados para classificar este ou aquele país americano como integrante dessa denominação. O cientista político e diplomata Alain Rouquié bem nos lembra que definir o conceito de América Latina em termos geográficos é impossível, e também o é do ponto de vista cultural, pois assim teríamos que incluir nesta denominação o Canadá francês, "infinitamente mais latino que Belize e tanto quanto Porto Rico, Estado livre associado aos Estados Unidos", mas que, nem por isso, "ninguém jamais pensou em incluí-lo, mesmo ao nível de sua província francófona, no subconjunto latino-americano"

Uma outra dificuldade que se nos aparece é o aspecto negativo de se abordar de maneira una e homogênea uma extensa regiáo que, na verdade, é extremamente diversificada do ponto de vista étnico, cultural, lingüístico, político e econômico. Sabemos que quando falamos em América Latina não estamos levando em consideração os povos originários da região, nem os povos africanos transplantados ao longo de séculos para cá. Ou melhor, estamos levando-os em consideração sim, mas na perspectiva de uma dominação que não os compreende como agentes do processo de formação de identidade do continente.

Portanto, para deixar este trabalho com menos arestas possíveis, precisamos deixar claro que não apresentaremos aqui a visão dos chamados "grupos excluídos" da História, pois conforme veremos mais adiante o termo América Latina não é gerado em seus discursos, mas sim nos da elite político-econômica criolla da América espanhola. Certamente esses "excluídos" foram importantes para o processo de criação identitária, mas o nosso foco de análise centra-se naquele último grupo.

Isto não significa que professamos um total desprezo pelo restante da população do continente. Muito pelo contrário, acreditamos que por meio da análise da criação da ideia de uma "América Latina" 
- forjada por uma minoria a partir do século XIX e presente até os nossos dias - poderemos começar a alterá-la, ou, quem sabe um dia, até ampliá-la, pois é na descoberta das verdadeiras motivaçóes que levaram à exclusão desses diversos grupos sociais que não tiveram vez ao longo da história da regiáo que poderemos agir em relação às mudanças necessárias.

Do que foi dito acima, depreende-se um aspecto que interessa particularmente a nós, brasileiros: a não participação do Brasil no processo de construção ideológica da América Latina. Por isso, não é nossa preocupação aqui examiná-lo no desenrolar de tal processo. Eventualmente iremos mencioná-lo, mas sem grandes pretensóes analíticas.

Como última observação, gostaríamos de deixar claro que para desenvolvermos nossa argumentação, optamos por deixar de lado aquela bibliografia que há tempos vem sendo exaustivamente analisada pelos pesquisadores do tema ${ }^{5}$, adotando como referência bibliográfica central Génesis de la idea y el nombre de América Latina ${ }^{6}$, do já falecido filósofo uruguaio Arturo Ardao. Nessa obra, publicada em 1980, e infelizmente ainda pouco conhecida do público brasileiro, Ardao busca explicar a construção da identidade latino-americana a partir do surgimento da noçâo e do nome América Latina ${ }^{7}$.

Seguiremos basicamente esta mesma proposta, qual seja a de mostrar o percurso evolutivo das principais denominações atribuídas ao longo da história à região. E teremos sempre as formulações de Ardao como eixo norteador deste ensaio, porém sem esquecer de cotejá-las com trabalhos de outros pesquisadores do tema, buscando assim problematizar um maior número de questóes possíveis.

São estas, portanto, as principais consideraçôes preliminares a se fazer. E é esta América Latina, tão imprecisa e complexa, que queremos abordar. Mesmo tendo em vista os diversos riscos que corremos ao propor esse tipo de análise, não podemos negar que existe, do ponto de vista geopolítico, uma região reconhecida mundialmente como sendo a América Latina, que alude "nos planos político e cultural a uma entidade autônoma, assim como Europa, Ásia, África ou América do Norte”.

\section{A gênese do nome "América"}

Comecemos entâo com um ponto que nos parece central no trabalho de Ardao: para explicar a construção da ideia e do nome de América Latina, temos que buscar as origens do nome "América", pois segundo o filósofo uruguaio a noção de "América Latina" é parte constitutiva da denominação".

Partindo desta premissa, Ardao argumenta que os processos de formação identitária, tanto da América, quanto da América Latina, podem ser divididos, cada um deles, em três etapas. Em uma primeira etapa, a característica predominante seria a ausência, não só de uma noção, mas também de um nome referentes ao recorte geográfico específico. A segunda etapa seria caracterizada pela percepção da existência de uma região específica, mas que ainda não tem um nome. Por último, tem-se a etapa na qual essa percepçáo passa a ser acompanhada por um nome que a expressa de maneira definitiva.

Para melhor compreendermos tal metodologia de análise, vamos analisar o caso do surgimento do nome "América". O processo de gênese de sua ideia e de seu nome (ou seja, o percurso das três etapas acima descritas) prolongou-se por aproximadamente quinze anos, tendo o seu início no momento imediatamente após a chegada de Colombo às Antilhas.

Ardao destaca que, antes de ser chamada de "América", a extensa faixa territorial conquistada pelos europeus foi denominada, primeiramente, de "Índias" e, posteriormente, de "Novo Mundo".

Quando da primeira fase, fica claro, pela denominação, que os navegantes ignoravam que se tratava de uma região desconhecida, inédita, na perspectiva européia. $\mathrm{O}$ próprio Colombo, que atribuiu tal nome por ter pensado que havia chegado às Índias, morreu acreditando piamente nesse equívoco.

Quando Américo Vespúcio faz suas viagens pelas terras avistadas por Colombo e percebe que, na verdade, o genovês havia chegado a uma região até então inexistente nos mapas europeus, cria-se a per- 
cepção da existência de uma regiáo específica, apesar do nome "América" ainda não se fazer presente. O termo utilizado para designar essa novidade foi "Novo Mundo", que, de acordo com Arturo Ardao, é "classificativo e qualificativo: classifica como Mundo, em seu sentido convencional, ao descoberto, e ao mesmo tempo o qualifica de Novo"10. Esta seria a segunda etapa do processo de gênese.

O nome "América" somente nasce em 1507, quando o geógrafo alemão Martin Waldseemüller publica Introdução à Cosmografia, contendo um mapa no qual o autor refere-se ao Novo Mundo como "América”, em uma clara homenagem a Américo Vespúcio.

A superação das três etapas que, neste caso, durou precisamente 15 anos - de 1492 a 1507 -, consolidou o nome "América", mas não excluiu a existência de outras nomenclaturas. Os europeus ainda utilizariam outros termos para se referirem ao continente americano por muitos e muitos anos. A própria expressão "Novo Mundo" continuou a ser empregada ainda por séculos, e continua até os dias de hoje (mesmo que com bem menos força do que antes) ${ }^{11}$, o que é justificado por Ardao pelo fato de "haver grande riqueza semântica em seu jogo dialético com o Velho Mundo [a Europa] - desde o geográfico e histórico até o filosófico" 12 .

Estabelecido o nome "América", é importante salientar que tal categoria não serviu aos interesses da elite colonial espanhola de imediato. Afirmamos isso porque a noção de "americano" não era partilhada por tal grupo até aproximadamente o início dos processos de independência da América espanhola - ou seja, até fins do século XVIII e início do século XIX.

O historiador francês François-Chavier Guerra, analisando com rigor o caso espanhol, afirma que os atritos entre as elites criollas e o poder metropolitano no início do século XIX contribuíram para que o estatuto da América e sua própria identidade fossem reformulados:

Até 1810, as elites criollas, na luta pela igualdade política, se apresentavam, antes de mais nada, como espanhóis iguais aos peninsulares que gozavam, além disso, dos privilégios e foros que lhes dava sua condição de descendentes dos conquistadores e povoadores da América. A partir de agora [1810], a necessidade de distinguir-se de seus inimigos levou os insurgentes a colocar em primeiro plano esta identidade "americana" que se havia consolidado em fins do século XVIII. ${ }^{13}$

Corroborando o enunciado acima, Miguel Rojas Mix afirma que "se durante a colônia o americano admitia ser chamado de 'criollo', 'indiano' ou 'espanhol das Índias', em começos do século XIX, associado aos processos de independência, o problema da identidade se apresenta sob uma nova perspectiva”, com o processo emancipatório terminando "por impor o nome de 'americano"' 14 .

Claro está que a auto-afirmação de "americano" corresponde a uma necessidade de se diferenciar do inimigo europeu e que a eficiência desse qualificativo, no processo de lutas de independência, foi considerável ${ }^{15}$. Entretanto, talvez mais importante do que isso seria o fato de que, tanto a criação, quanto a divulgação desse conceito representavam a necessidade de se implantar uma identidade continental nas ex-colônias, pois assim se estabeleceria a criação de uma grande força responsável pela defesa contra possíveis ataques das antigas metrópoles européias ${ }^{16}$. Certamente essas ações eram praticadas quase que exclusivamente pelos grupos situados no topo da pirâmide social da regiáo recém-liberta, mas isso não diminui sua importância no processo de consolidação de uma futura identidade latino-americana, uma vez que esta também foi "construída" de cima para baixo, conforme veremos mais adiante.

\section{Da "Hispanoamérica” à "América Latina": o papel dos Estados Unidos}

Paralelamente à consolidação da ideia de "americano", na América espanhola da pós-independência observa-se um fenômeno curioso: a mudança da utilização do termo "América" por "Hispanoamérica" no discurso dos líderes dos movimentos emancipatórios e das novas elites ${ }^{17}$. Apesar de Simón Bolivar 
empregar o termo "América" na Conferência do Panamá de 1826, nos anos subseqüentes o ideal de construção de uma "Hispanoamérica" passou a ser predominante; essa mudança é relevante, quando se busca compreender o processo de gênese do nome "América Latina".

O historiador Aimer Granados Garcia explicita bem essa transição quando analisa os conteúdos dos congressos de união continental realizados na América hispânica ao longo das primeiras décadas posteriores à Independência ${ }^{18}$. Em meio a uma fase difícil da história das antigas colônias espanholas, marcada pela conturbada construção das futuras naçóes das Américas Central e do Sul, a mudança de "América" para "Hispanoamérica" não teria sido inocente. No fundo, tal mudança teria obedecido "a uma maior consciência do que constituía a identidade cultural do grupo de países que formavam a antiga América espanhola”, e que "em função das constantes tentativas de agressão de que eram objeto desde o momento da Independência, tentavam se mostrar perante a comunidade internacional como países livres e unidos por uma série de interesses e vínculos culturais" ${ }^{\prime 1}$.

Entretanto, quais eram essas tentativas de agressão que enfrentavam as ex-colônias espanholas no período posterior a suas independências, mencionadas acima por Granados Garcia? A resposta a esta pergunta também é fundamental para a nossa busca arqueológica da construção do nome "América Latina".

Em linhas gerais, podemos afirmar que os inimigos das nascentes repúblicas hispano-americanas eram basicamente algumas potências européias e os Estados Unidos. Entre todas elas, a que merece mais destaque é esta última nação, em função dos propósitos deste artigo.

Os Estados Unidos despontavam no século XIX como uma potência regional. A partir da criação da Doutrina Monroe em 1823, com seu lema "A América para os americanos", suas ambiçóes imperialistas em relação aos países do continente ficaram claras. Tratando-se apenas, inicialmente, de uma advertência às potências européias, no sentido de que não tentassem reativar o domínio colonial sobre o continente, essa doutrina passou a ser empregada, ainda no século XIX, como justificativa intervencionista para todo o continente americano. Seu lema poderia ser interpretado, portanto, como "A América para os norte-americanos".

A força de seu imperialismo regional pôde ser sentida pelo México no final dos anos 1840, quando da guerra travada pelos dois países e que teve como saldo a cessão aos Estados Unidos de aproximadamente 2,4 milhôes de quilômetros quadrados do território mexicano. Além disso, vale lembrar a façanha de William Walker (1824-1860), norte-americano que, a partir de 1855, passou a ser o grande chefe político da Nicarágua.

Segundo Arturo Ardao, a então emergente "hispanoamericanidade" apareceu no contexto dessa luta, quando se procurava "definir e afirmar a identidade comum frente aos Estados Unidos, o jovem império que ameaçava a partir da América e com o nome de América" "20. A parte final deste comentário de Ardao parece muito interessante, já que chama atenção para a "apropriação" do termo "América" pelos norte-americanos. Esse fato também teria contribuído para a definição de um outro termo que denominasse a antiga América espanhola, conforme explicitado nas palavras de José Maria Samper, publicadas em 1861, ao justificar o porquê da necessidade de se inovar a terminologia "histórico-geográfica do Novo Mundo", uma vez que:

os cidadãos da Confederação do Norte chamada "Estados Unidos", atribuíram a si mesmos e com razão, o nome de Americanos, como expressão de sua nacionalidade política, assim como designam com o nome genérico de América a Confederação fundada por Washington (... $)^{21}$.

Chegamos assim ao momento-chave da trajetória do nome "América Latina", por tratar-se da ocasiáo em que a necessidade de definir uma nova identidade, face à presença dos Estados Unidos, favoreceu o aparecimento de novos termos identitários para a América hispânica. Diversos nomes vieram à tona ao longo da busca dessa identidade, como por exemplo, Magna Colômbia, proposto ainda em fins do século XVIII pelo militar venezuelano Francisco de Miranda - considerado um dos precursores dos movimentos de independência da América espanhola - e que em meados do século XIX ainda era 
defendido por alguns intelectuais como a melhor definição para a regiáo ${ }^{22}$. Contudo, dentre todos os nomes que surgiram ao longo desse período, o termo "América Latina" foi sem dúvida aquele que mais logrou êxito, pois ao contrário dos demais, perpetua-se até os dias de hoje.

Em função da relevância dos Estados Unidos nesse processo de consolidação do termo "América Latina", concordamos com Arturo Ardao quando ele afirma que náo podemos compreendê-lo em sua totalidade sem nos balizarmos pela expressão que de certa forma é a sua antítese: a "América Saxônica". Como afirma Ardao, América Latina e América Saxônica "são conceitos correlacionados, ainda que por oposição; não puderam aparecer e se desenvolver a não ser juntos, mesmo que por contraste" 23 . Esta dualidade, que "parte diretamente da filiação étnica das populaçôes de origem europeia que implantaram em terra americana determinadas formas de cultura" ${ }^{24}$, não se expressa dessa maneira na linguagem cotidiana, visto que náo nos referimos aos americanos dos Estados Unidos como "saxoamericanos", mas sim como norte-americanos. Entretanto, por mais que a dualidade mais apropriada seja América Latina /América do Norte, ela se fundamenta no critério do conglomerado étnico do qual a nação-mãe faz parte: saxônico, no caso inglês; latino, nos casos português, espanhol e francês.

Feita esta ressalva, e tendo-a como referência daqui em diante, veremos como se apresenta o debate historiográfico acerca da gênese do nome "América Latina".

\section{"América Latina” no campo da História das Ideias: John Leddy Phelan, Arturo Ardao e Miguel Rojas Mix}

Como informamos no início deste ensaio, a obra de Ardao, Génesis de la idea y el nombre de América Latina, é a nossa mais importante referência para a abordagem da construção do nome "América Latina”. Talvez a principal justificativa de nossa atitude seja o fato de que por meio desta obra, Ardao conseguiu revisar e alterar uma perspectiva paradigmática que era predominante desde, pelo menos, fins dos anos 1960. Ao trazer à tona um assunto que para muitos estava encerrado, o filósofo uruguaio abriu novas possibilidades para pesquisas em torno do mesmo tema; e já a partir dos anos 1990 novos argumentos apareceram, alguns até mesmo refutando-o.

Tratemos, agora, de discutir as análises de mais dois estudiosos do assunto que chegaram a conclusóes diferentes das do filósofo uruguaio. Ao procedermos desta maneira, buscamos integrar a obra de Ardao em um contexto historiográfico mais amplo, além de examinarmos as linhas centrais deste debate. Comecemos, pois, por aquele que iniciou a discussão sobre o assunto.

O ponto de partida da arqueologia do nome "América Latina" se inicia com o artigo do historiador norteamericano John Leddy Phelan, "Pan-Latinism, French Intervention in Mexico (1861-1867) and the Genesis of the Idea of Latin América", publicado em 196825. Seu impacto no meio acadêmico foi enorme, podendo ser considerado até os dias de hoje como a referência bibliográfica predominante sobre o tema ${ }^{26}$.

Neste artigo, Phelan considera que o termo "América Latina" aparece pela primeira vez em 1861, no contexto do panlatinismo. A ideologia panlatina, que já existia na França desde os anos 1830, ganhando força no governo de Napoleão III (o chamado Segundo Império, de 1852 a 1870), objetivava subjugar as naçóes hispano-americanas ao poderio francês, e ao mesmo tempo visava diminuir a área de atuação da política imperialista dos Estados Unidos. Seu ponto central era a aproximação cultural entre a França e as nascentes repúblicas de língua espanhola, a partir de uma união "latina" intercontinental, mas que obviamente teria a França como liderança.

John Leddy Phelan destaca o papel do político e economista francês Michel Chevalier (1806-1879) no processo de elaboração do termo "América Latina". Um dos principais ideólogos do panlatinismo, Chevalier já pensava a existência de uma América latina, com "l" minúsculo, muito antes do reinado de Napoleão III, mais precisamente em 1836, conforme é possível ler na introdução de sua obra Lettres sur l'Amerique du Nord: "Os dois troncos, latino e germânico, se reproduziram no Novo Mundo. A 
América do Sul é, como a Europa, meridional, católica e latina. A América do Norte pertence a uma população protestante e anglo-saxônica ${ }^{27 ”}$.

Temendo o crescimento imperial dos Estados Unidos e da Rússia e a conseqüente superação dos franceses nessa disputa, Chevalier esclarece o papel de liderança da França no panlatinismo:

A França (...) constitui o topo do grupo latino; é seu protetor. Nos acontecimentos que parecem se aproximar, o papel da França é grande. A França é depositária dos destinos de todas as naçóes do grupo latino nos dois continentes. Somente ela pode impedir que esta família inteira de povos não seja tragada pelo duplo avanço dos Germanos, ou Saxóes, e dos Eslavos. ${ }^{28}$

Segundo Phelan - e com esse ponto Ardao parece concordar -, é a partir daqui que nasce não o nome "América Latina”, mas sim a noção de uma "América Latina", o que por sua vez nos permite concluir que aqui ocorre o momento de criação da dualidade América Latina / América Saxônica já mencionada.

Desta ideia de Michel Chevalier constrói-se o panlatinismo francês que, com o passar dos anos, aos poucos, vai sofrendo alteraçôes. Quando do governo de Napoleâo III, presidente da república francesa a partir de 1848 e autoproclamado imperador a partir de 1852, inúmeros intelectuais franceses e até mesmo hispano-americanos abraçaram o conceito de panlatinismo, cada um por motivaçóes diferentes. Os primeiros por uma razão óbvia: a ampliação do império francês, como que uma espécie de volta ao Antigo Sistema Colonial, ou antecipação do neocolonialismo de fins do século XIX. Os hispano-americanos, por uma questão também estratégica, mas com propósitos bem diferentes dos primeiros: o desejo de construir a ideia de um "nós" europeu ${ }^{29}$ que permitisse a saída do "atraso" e o ingresso na "civilização".

Como conseqüência mais marcante desse panlatinismo, enquanto manifestação imperialista, observa-se, além de alguns projetos que fracassaram ${ }^{30}$, a invasão do México pelos franceses em 1862. Aproveitando a fraqueza dos Estados Unidos, em virtude da Guerra de Secessão (1861-1865), Napoleão III invade militarmente uma parte do território mexicano, e para garantir seu predomínio na região acaba por nomear o arquiduque austríaco Maximiliano de Habsburgo como monarca daquele país.

Segundo Phelan, foi à época dos preparativos da invasão francesa ao território mexicano que nasceu o termo "América Latina", em um artigo de 1861 escrito por L. M. Tisserand na Revue des Races Latines ${ }^{31}$, publicação que circulou em Paris entre os anos de 1857 e 1861, com uma orientação panlatina. Rapidamente, o termo foi apropriado por outros intelectuais franceses e por alguns hispanoamericanos residentes na Europa.

Esse artigo de John Leddy Phelan foi duramente criticado por Arturo Ardao doze anos depois, em Génesis de la idea y el nombre de América Latina. Ao lançar uma nova interpretação no campo de estudos acerca da criação do conceito de América Latina, Ardao, inevitavelmente, acabou por confrontar a visão do historiador norte-americano, sustentando que o nome "América Latina" não havia sido criado pelos franceses, mas sim pelo pensador e jornalista colombiano, residente em Paris, José Maria Torres Caicedo (1830-1889), no ano de 1856.

Partindo da premissa de que o processo de criação da noção e do nome "América Latina" durou aproximadamente 50 anos, Ardao inicia sua argumentaçáo apresentando aquela que considera como a primeira etapa da gestação: entre o início das independências e os anos 1830 náo existia nem ao menos o conceito de "América Latina"; os termos utilizados à época para se referir a região eram "América Meridional", "América do Sul", "América", "Hispanoamérica".

A segunda etapa desse processo, ainda de acordo com Ardao, se desenvolveu entre os anos 1830 e os 1850; trata-se do momento de criação da ideia de América Latina, mas não de seu nome. Concordando com Phelan, Ardao afirma que ela apareceu primeiramente em alguns textos de escritores franceses, quando estes começaram a distinguir no continente americano duas etnias (ou duas "raças", como se dizia à época): uma latina e outra saxônica. Um nome emblemático que ilustraria bem esse argumento seria o de Michel Chevalier, o mesmo analisado por Phelan e já mencionado anteriormente. 
Ardao ainda acrescenta que nessa fase os americanos de origem espanhola (hispanoamericanos) residentes na Europa (principalmente em Madrid e Paris) passaram a incorporar esta ideia, mas sempre com o termo "latino" servindo de conotação à América de língua espanhola. Ficavam excluídos, assim, os americanos de origem portuguesa e francesa.

Por fim, a última etapa é a da criação do nome em si, que começou na segunda metade dos anos 1850, com José Maria Torres Caicedo. Em Paris desde 1853, o jornalista colombiano publica, em setembro de 1856, na capital francesa um poema intitulado "Las dos Américas" que traz os seguintes versos:

La raza de la América latina

$\mathrm{Al}$ frente tiene la sajona raza,

Enemiga mortal que ya amenaza

Su libertad destruir y su pendón ${ }^{32}$

Este seria, segundo Arturo Ardao, o "certificado de batismo" - para empregar a expressão de Phelan ${ }^{33}$ de "América Latina", já que o termo "latina" não mais é aplicado como adjetivo, mas sim como substantivo. Mesmo não abandonando em seus escritos os termos "América do Sul", "Hispanoamérica" e "América Espanhola", ainda nos anos 1850, Torres Caicedo utilizará inúmeras vezes a expressão "América Latina" e suas variaçôes, tais como "Estados latino-americanos", "naçôes latino-americanas", "Estados da América latina", "Repúblicas da América latina". Por isso Ardao conclui que "antes do fim da década de 50, na pena hispanoamericana de Torres Caicedo, não só chegou a existir como que se encontrava em circulaçáo e, portanto, em processo de difusão, o nome - como nome - de América Latina”34.

Há apenas um tópico em que Ardao e Phelan parecem concordar em relação ao processo de gênese: trata-se do contexto histórico e geográfico em que aquele se deu, isto é, o do panlatinismo da França de meados do século XIX. Mas, as divergências distanciam-nos enormemente. A primeira parece óbvia: cinco anos antes de L. M. Tisserand escrever o termo "L'Amerique Latine", Torres Caicedo, em 1861, já o havia criado (em espanhol) e o difundido na própria França, em diversos escritos.

O segundo ponto de atrito, mas não menos importante do que o primeiro, é perceptível nos versos de Torres Caicedo, acima citados. A identificação da regiáo outrora chamada "hispanoamericana", na perspectiva do jornalista colombiano, teria resultado da ameaça representada pelos Estados Unidos, e não como mera justificativa da invasão mexicana pela França, conforme as palavras de Tisserand, um francês - tese defendida por John Phelan.

Neste debate entre Ardao e Phelan, parecia que o primeiro havia anulado a perspectiva analítica do segundo, pondo fim à discussão. Mas, mesmo com um forte embasamento documental para justificar seu argumento, Ardao não se viu livre de críticas; no início dos anos 1990, com o lançamento de um livro do historiador chileno Miguel Rojas Mix, suas conclusôes passaram a ser questionadas.

Rojas Mix publica, em 1991, Los cien nombres de América ${ }^{35}$, apresentando uma interessante listagem dos diversos nomes atribuídos ao continente americano, pelo menos em sua parte de origem espanhola e portuguesa. Quando analisa a origem do nome "América Latina", ele discute a visão equivocada de Phelan, contrastando-a com a de Ardao.

Entretanto, Rojas Mix afirma que Ardao também se equivocara ao desconsiderar o pensamento do intelectual chileno Francisco Bilbao (1823-1865) que, entre os anos de 1855 e 1857 residira em Paris. Ele propagava, assim como alguns intelectuais hispanoamericanos exilados na França, a uniáo dos povos das repúblicas de origem espanhola para fazer frente ao imperialismo ianque. Porém, segundo Rojas Mix, em junho de 1856 - ou seja, três meses antes de Torres Caicedo - o pensador chileno teria criado o termo "América Latina" durante uma conferência em Paris.

Suas palavras foram posteriormente transcritas, sob o título "Iniciativa de la América. Idea de un Congreso Federal de las Republicas"36, e nelas encontramos a seguinte afirmação: "Pero la América vive, la América latina, sajona e indígena protesta, y se encarga de representar la causa del hombre 
(...)"37. Aqui estaria a origem do nome "América Latina", defende Rojas Mix, e não na poesia de Torres Caicedo. Este seria, portanto, o grande equívoco de Ardao, segundo o historiador chileno: ter concedido a autoria dessa nova atribuição de sentido à expressão América Latina a outro indivíduo.

Contudo, Ardao não chegou a ignorar Francisco Bilbao, pois em seu Génesis de la idea y el nombre de América Latina dedicou aproximadamente uma página e meia à análise de suas palavras ${ }^{38}$. Entretanto, o filósofo uruguaio não as reconheceu como o momento da criação do termo, pois, para ele, Bilbao ainda estaria usando o termo "latina" como um adjetivo, e náo como um substantivo. Além disso, a denominação que Bilbao atribui ao continente, no restante de seu texto, é o de América do Sul. Apesar disso, Ardao preocupa-se em afirmar que as palavras do intelectual chileno merecem um lugar privilegiado na história do advento da ideia de uma América Latina ${ }^{39}$.

Porém, para Rojas Mix, esta negação é insustentável e, no fundo, exprime o preconceito de historiadores e filósofos da região, ainda nos dias de hoje, para com Francisco Bilbao, já que ele foi "um marginal da história, um personagem subversivo, difícil de encarar" ${ }^{40}$. Além desse preconceito, um outro motivo que justificaria a negação de sua precedência na autoria da denominação teria sido a atitude do pensador chileno, abandonando o termo pouco tempo depois de enunciá-lo, em virtude de sua decepção com a invasão francesa do México, no início dos 1860. Essa atitude não foi seguida por Torres Caicedo; muito pelo contrário, o jornalista colombiano foi um dos seus grandes divulgadores até o fim da vida, e isto lhe trouxe um maior reconhecimento ${ }^{41}$.

Sem negar que Torres Caicedo tenha empregado a expressão "América Latina" em seu poema Las dos Américas - embora sempre enfatizando que isto acontecera somente três meses depois do congresso organizado por Bilbao -, Rojas Mix sustenta que não se trata de mera coincidência, mas, talvez, de um caso de plágio. Torres Caicedo pode tê-la ouvido da própria boca de Bilbao, quando da realização da mencionada conferência em Paris, utilizando-a, depois, em sua obra.

Não há nenhuma documentação que comprove a participação do colombiano no evento, mas Rojas Mix adverte que, para aquele encontro, foram convidados os intelectuais hispanoamericanos residentes em Paris e que, como eles não eram numerosos à época e todos se conheciam bem, é difícil acreditar que Torres Caicedo não estivesse ali presente, ou pelo menos não soubesse do que foi entáo discutido. Indo um pouco mais além, Rojas Mix defende a tese do plágio destacando que Torres Caicedo, conforme reconhece o próprio Ardao, apenas nove dias antes da conferência, escreveu um artigo ${ }^{42}$ no qual utilizou o termo "América Espanhola" para se referir à regiáo ${ }^{43}$. Seria uma estranha coincidência ele ter passado a utilizar o termo "América Latina" após a realização desse encontro.

Criticando outros autores que defendem a tese de Ardao, Rojas Mix parte para uma conclusão direta, na qual não somente defende veementemente seu compatriota, como também propóe uma reavaliação do assunto por parte dos estudiosos:

Não é justificável escamotear, ou minimizar, o papel de Bilbao na fundação do termo em que hoje reconhecemos nossa identidade. Não só porque foi o primeiro a utilizá-lo, mas também porque ele lhe deu o seu sentido atual - muito distante das concepções de latinidade de entáo (...) Não se trata de desprezar o colombiano [Torres Caicedo], que foi quem mais fez para difundir a ideia, mas não se pode esquecer do chileno porque, além disso, foi ele quem melhor entendeu esta denominação como um paradigma de identidade anticolonial e anti-imperialista. Inclusive o fato de ter deixado de utilizá-la é coerente e mostra a estreita ligação que estabelecia entre este nome e a decisão anti-imperialista. Quando o abandona é porque percebe que serve para legitimar o colonialismo francês. ${ }^{44}$

Como resultado do debate entre Ardao e Rojas Mix podemos concluir que, independentemente das divergências existentes entre eles, fica claro que o certificado do nascimento do termo "América Latina" coube aos intelectuais hispanoamericanos. Assim, a tese de Phelan parece não ter mais validade. 


\section{Nota sobre o debate de Phelan, Ardao e Rojas Mix no Brasil}

Esse debate acerca da criação do termo "América Latina" parece ser ainda pouco conhecido no meio acadêmico internacional e mais ainda no brasileiro. Dos raros pesquisadores brasileiros que se interessam, ou se interessaram, por esse tópico, praticamente todos parecem desconhecer a tese proposta por Rojas Mix. Do que tivemos a oportunidade de examinar, somente o historiador Luis Alberto Moniz Bandeira aparece como exceção, por atribuir a criação do nome a Francisco Bilbao ${ }^{45}$.

No interessantíssimo A história do conceito de "Latin América" nos Estados Unidos, João Feres Jr. analisa com rigor e brilhantismo a trajetória do nome, comentando o debate Arturo Ardao versus John Phelan; mas as conclusóes de Miguel Rojas Mix não são sequer citadas. Vários pesquisadores - entre os quais, Hector Bruit ${ }^{46}$, por muitos anos professor de História da América da Unicamp - ainda defendem a visão de Phelan, parecendo desconhecer a tese de Ardao. Outros parecem desconhecer até mesmo o pioneiro artigo do historiador norte-americano ${ }^{47}$.

Talvez esse descaso dos pesquisadores brasileiros em relação ao tema se deva ao fato de que o país, realmente, não tenha uma tradição de pesquisas na área de Américas. Esforços em vários sentidos vêm sendo realizados nas últimas décadas pelas principais universidades brasileiras, mas o caminho a ser trilhado parece ser ainda longo.

\section{Conclusão}

A sobrevivência do termo "América Latina" e sua utilização ainda nos dias de hoje não constituem fatos óbvios. É importante ressaltar que esse nome enfrentaria altos e baixos ao longo do final do século XIX. As explicaçôes para isso são inúmeras; dentre elas podemos destacar a própria presença do imperialismo francês nas Américas de língua espanhola. O fracasso desse projeto, entretanto, não impediu o surgimento de um sentimento de repulsa ao panlatinismo, pela inevitável associaçáo com o imperialismo. Além disso, e talvez como conseqüência do motivo anterior, observa-se a ascensão de outras ideologias identitárias no continente americano, tais como a volta do hispanoamericanismo, com José Enrique Rodó e seu clássico Arie $^{48}$, e o fortalecimento do panamericanismo - encabeçado pelos Estados Unidos -, ambos em fins do século XIX.

O certo é que após a Segunda Guerra Mundial, o termo "América Latina” ganhou impulso e se consolidou, principalmente por meio da ação dos organismos políticos multilaterais ${ }^{49}$. Compreender as motivaçóes daquele momento, contudo, é tarefa para outra pesquisa.

Para encerrar, gostaríamos de frisar que a busca de uma identidade latino-americana, ou das identidades latino-americanas, tem sido objeto, há quase dois séculos, das preocupaçóes de seus (ou nossos?) intelectuais ${ }^{50}$. Logo, essa busca parece infinita, pois se reconstrói de acordo com os interesses dos seus mais variados grupos, em determinados contextos históricos. Mesmo assim, sempre continuaremos a definir as nossas e as outras identidades.

Arturo Ardao resume esse aspecto demonstrando como a busca por um nome que nos identifique é fundamental. Ao analisar a tentativa de se revitalizar a clássica ideia mirandina de "Magna Colombia", em meados do século XIX, o filósofo uruguaio afirma:

(...) não se tratou de um ato de romantismo histórico, embora se estivesse na época romântica. Foi, pelo contrário, um episódio a mais no longo empenho de nossa América, como gostava de dizer Martí (...), em definir sua identidade através da determinação de seu nome. Esse empenho é carregado de drama. As sucessivas geraçôes, desde fins do século XVIII até os nossos dias, o vêm sentindo, cada uma a seu modo, mas sempre sob a necessidade de se dar resposta aos desafios à autonomia de sua personalidade comum. Ou seja, à sua própria existência. Não saber como se chamar é algo maior do que não saber como se é; é não saber quem se é. ${ }^{1}$ 
AmÉRICA LATINA: DA CONSTRUÇÃO DO NOME À CONSOLIDAÇÃO DA IDEIA

Rafael Leporace Farret e Simone Rodrigues Pinto

\section{Notas}

${ }^{1}$ Ver MIGNOLO, Walter. La idea de América Latina. La herida colonial y la opción decolonial. Barcelona: Gedisa Editorial, 2005.

${ }^{2}$ Referência à obra $A$ Tempestade, de Shakespeare, em que Caliban representa o nativo bárbaro e subjugado por um europeu, o Duque de Milão, Próspero.

${ }^{3}$ Cf. ROJAS MIX, Miguel. Los cien nombres de América. Barcelona: Editorial Lumen, 1991. p. 61-62.

${ }^{4}$ Cf. ROUQUIÉ, Alain. O Extremo-Ocidente: introdução à América Latina. São Paulo: EDUSP, 1991. p. 21.

${ }^{5}$ Como, por exemplo, A invenção da América, de Edmund O’Gorman (São Paulo: Editora da UNESP, 1992), e A conquista da América, de Tzvetan Todorov (São Paulo: Martins Fontes, 1996).

${ }^{6}$ Ver ARDAO, Arturo. Génesis de la idea y el nombre de América Latina. Caracas: Centro de Estudios Latinoamericanos Romulo Gallegos, 1980.

${ }^{7}$ Para Ardao, a ideia de América Latina e o nome que a expressa são dois signos diferentes que merecem ser analisados separadamente.

${ }^{8}$ Cf. ARDAO, Arturo. Génesis de la idea y el nombre de América Latina, op. cit., p. 16.

${ }^{9}$ Idem, ibidem, p. 31.

${ }^{10}$ Idem, ibidem, p. 17.

${ }^{11}$ A título de exemplo, ver, de Carmen Bernand e Serge Gruzinski, Histoire du Nouveau Monde (Paris: Fayard, 1991-1993, 2 vols.), lançado recentemente no Brasil pela EDUSP, com o título de História do Novo Mundo.

${ }^{12}$ Cf. ARDAO, Arturo. Génesis de la idea y el nombre de América Latina, op. cit., p. 17.

${ }^{13}$ Cf. GUERRA, François-Xavier. Las mutaciones de la identidad en la América Hispánica. In: GUERRA, François-Xavier y ANNINO, Antonio (Coords.). Inventando la nación. Mexico: Fondo de Cultura Económica, 2003. p. 210.

${ }^{14}$ Cf. ROJAS MIX, Miguel. Los cien nombres de América, op. cit., p. 63-64.

${ }^{15}$ Cf. GUERRA, François-Xavier. Modernidad y independencias. Ensayos sobre las revoluciones hispánicas. 3.ed. Mexico: Ed. Mapfre / Fondo de Cultura Económico, 2000. p. 348.

${ }^{16}$ Cf. GRANADOS GARCIA, Aimer. Congresos e intelectuales en los inicios de un proyecto y de una conciencia continental latinoamericana, 1826-1860. In: GRANADOS GARCIA, Aimer. y MARICHAL, Carlos (Comp.). Construcción de las identidades latinoamericanas. Ensayos de historia intelectual, siglos XIX y XX. México: El Colegio de México, 2004. p. 42.

${ }^{17}$ Cf. ROJAS MIX, Miguel. Los cien nombres de América, op. cit., p. 64.

${ }^{18}$ Além do já mencionado Congresso do Panamá, em 1826, poderíamos destacar os congressos de Lima, realizado em 1848 , e o de Santiago do Chile, em 1856.

${ }^{19}$ Cf. GRANADOS GARCIA, Aimer. Congresos e intelectuales en los inicios de un proyecto y de una conciencia continental latinoamericana, 1826-1860, op. cit., p. 53. Rojas Mix parece concordar com Granados Garcia, ao afirmar que "esta hispanoamericanidade se define pelo único vínculo importante deixado pela dominação espanhola: a língua. Conseqüentemente, é vista como uma comunidade cultural formada pelas repúblicas, antigas colônias espanholas". Cf. ROJAS MIX, Miguel. Los cien nombres de América, op. cit., p. 64-65.

${ }^{20}$ Cf. ARDAO, Arturo. La idea de la Magna Colombia en Miranda y Hostos. In: ZEA, Leopoldo (Comp.). Fuentes de la cultura latinoamericana. Tomo I. México: Fondo de Cultura Económica, 1995. p. 46.

${ }^{21}$ Apud ARDAO, Arturo. La idea de la Magna Colombia en Miranda y Hostos, op. cit., p. 48.

${ }^{22}$ Ver ARDAO, Arturo. La idea de la Magna Colombia en Miranda y Hostos, op. cit.

${ }^{23}$ Cf. ARDAO, Arturo. Génesis de la idea y el nombre de América Latina, op. cit., p. 24.

${ }^{24}$ Idem, ibidem, p. 21.

${ }^{25} \mathrm{O}$ artigo foi publicado primeiramente em inglês, no ano de 1968, mas já em 1969 foi traduzido para o espanhol. Existe atualmente uma versão em espanhol disponível na coletânea de artigos organizados por Leopoldo Zea, Fuentes de la cultura latinoamericana (México: FCE, 1995, Tomo 1), sob o título de "El origen de la idea de Latinoamérica". Esta é a versão que discutimos aqui.

${ }^{26}$ Cf. GRANADOS GARCIA, Aimer. Congresos e intelectuales en los inicios de un proyecto y de una conciencia continental latinoamericana, 1826-1860, op. cit., p. 41.

${ }^{27}$ Cf. CHEVALIER, Michel. Sobre el progreso y porvenir de la civilización. 1836. In: ARDAO, Arturo. Génesis de la idea y el nombre de America Latina, op. cit., p.162.

${ }^{28}$ Idem, ibidem, p. 165. 
${ }^{29}$ Cf. SORIA, Esther Aillón. La política cultural de Francia en la génesis y difusión del concepto L’Amerique Latine, 18601930. In: GRANADOS GARCIA, Aimer y MARICHAL, Carlos (Comp.). Construcción de las identidades latinoamericanas. Ensayos de historia intelectual, siglos XIX y XX, op. cit., p. 72.

${ }^{30}$ Exemplos destes fracassos são o projeto de construção de um canal marítimo no Panamá, ligando os oceanos Pacífico e Atlântico, e a criação do Reino dos Andes.

${ }^{31}$ Cf. PHELAN, John Leddy. El origen de la idea de Latinoamérica. In: ZEA, Leopoldo (Comp.). Fuentes de la cultura latinoamericana. Tomo I. México: Fondo de Cultura Económica, 1993. p. 138.

${ }^{32}$ Apud ARDAO, Arturo. Génesis de la idea y el nombre de América Latina, op. cit., p. 182.

${ }^{33}$ Cf. PHELAN, John Leddy. El origen de la idea de Latinoamérica, op. cit., p. 473.

${ }^{34}$ Cf. ARDAO, Arturo. Génesis de la idea y el nombre de América Latina, op. cit., p. 86.

${ }^{35}$ ROJAS MIX, Miguel. Los cien nombres de América. Barcelona: Editorial Lumen, 1991.

${ }^{36}$ A edição que examinamos aqui é a publicada no volume organizado por ZEA, Leopoldo. Fuentes de la cultura latinoamericana, op. cit, p. 53-66.

${ }^{37}$ Cf. BILBAO, Francisco. Iniciativa de la América. Idea de un congreso federal de las repúblicas. In: ZEA, Leopoldo (Comp.). Fuentes de la cultura latinoamericana. Tomo I. México: Fondo de Cultura Económica, 1995. p. 56.

${ }^{38}$ Cf. ARDAO, Arturo. Génesis de la idea y el nombre de América Latina, op. cit., p. 81-82.

${ }^{39}$ Idem, ibidem, p. 82.

${ }^{40}$ Cf. ROJAS MIX, Miguel. Los cien nombres de América, op. cit., p. 345.

${ }^{41}$ Idem, ibidem, p. 344.

${ }^{42} \mathrm{O}$ texto em questão é o artigo "Agresiones de los Estados Unidos”, publicado no periódico El Correo Ultramar, em 15 de junho de 1856. Parte do artigo pode ser lida em ARDAO, Arturo. Génesis de la idea y el nombre de América Latina, op. cit., p. 80 .

${ }^{43}$ Cf. ROJAS MIX, Miguel. Los cien nombres de América, op. cit., p. 345.

${ }^{44}$ Idem, ibidem, p. 346.

${ }^{45}$ Ver MONIZ BANDEIRA, Luiz Alberto. ¿¿America latina o Sudamerica? Buenos Aires: Clarin, edição de 6/5/2005.

${ }^{46}$ BRUIT, Héctor Hernán. A invenção da América Latina. In: V Encontro da ANPHLAC. Disponível em <http://anphlac. cjb.net> Acesso em 19/07/09.

${ }^{47}$ Ver DINIZ, Dilma Castelo Branco. O conceito de América Latina: uma visão francesa. Caligrama. Revista de Estudos Românicos. Belo Horizonte, n. 12, 2007. p. 129-148.

${ }^{48}$ Cf. ROJAS MIX, Miguel. Los cien nombres de América, op. cit., p. 362.

${ }^{49}$ Ver MONIZ BANDEIRA, Luiz Alberto. ¿America latina o Sudamerica? op. cit.

${ }^{50}$ Cf. GRANADOS GARCIA, Aimer. y MARICHAL, Carlos (Comp.). Construcción de las identidades latinoamericanas, op. cit., p. 12.

${ }^{51}$ Cf. ARDAO, Arturo. La idea de la Magna Colombia en Miranda y Hostos, op. cit., p. 46.

\section{Referências bibliográficas}

ARDAO, Arturo. Génesis de la idea y el nombre de América Latina. Caracas: Centro de Estudios Latinoamericanos Romulo Gallegos, 1980.

. La idea de la Magna Colombia en Miranda y Hostos. In: ZEA, Leopoldo (Comp.). Fuentes de la cultura latinoamericana. Tomo I. México: Fondo de Cultura Económica, 1995. p. 33-49.

BILBAO, Francisco. Iniciativa de la América. Idea de un congreso federal de las repúblicas. In: ZEA, Leopoldo (Comp.). Fuentes de la cultura latinoamericana. Tomo I. México: Fondo de Cultura Económica, 1995. p. 51-66.

BRUIT, Héctor Hernán. A invenção da América Latina. In: V Encontro da ANPHLAC. Disponível em $<$ http://anphlac.cjb.net> Acesso em 19/07/09.

CHEVALIER, Michel. Sobre el progreso y porvenir de la civilización. 1836. In: ARDAO, Arturo. Génesis de la idea y el nombre de America Latina. Caracas: Centro de Estudios Latinoamericanos Romulo Gallegos, 1980. p. 155-167. 
DINIZ, Dilma Castelo Branco. O conceito de América Latina: uma visão francesa. Caligrama. Revista de Estudos Românicos. Belo Horizonte, n. 12, 2007. p. 129-148.

FERES JR., João. A história do conceito de "Latin América" nos Estados Unidos. Bauru: EDUSC, 2005.

GRANADOS GARCIA, Aimer. Congresos e intelectuales en los inicios de un proyecto y de una conciencia continental latinoamericana, 1826-1860. In: GRANADOS GARCIA, Aimer. y MARICHAL, Carlos (Comp.). Construcción de las identidades latinoamericanas. Ensayos de historia intelectual, siglos XIX y XX. México: El Colegio de México, 2004. p. 39-70.

GRANADOS GARCIA, Aimer y MARICHAL, Carlos (Comp.). Introducción. In:

Construcción de las identidades latinoamericanas. Ensayos de historia intelectual, siglos XIX y XX. México: El Colegio de México, 2004. p. 11-34.

GUERRA, François-Xavier. Modernidad y independencias. Ensayos sobre las revoluciones hispánicas. 3.ed. Mexico: Ed. Mapfre / Fondo de Cultura Económico, 2000.

Las mutaciones de la identidad en la América Hispánica. In: GUERRA, François-Xavier y ANNINO, Antonio (Coords.). Inventando la nación. Mexico: Fondo de Cultura Económica, 2003. p. $185-220$.

MIGNOLO, Walter. La idea de América Latina. La herida colonial y la opción decolonial. Barcelona: Gedisa Editorial, 2005.

MONIZ BANDEIRA, Luiz Alberto. ¿America latina o Sudamerica? Buenos Aires: Clarin, edição de $6 / 5 / 2005$.

PHELAN, John Leddy. El origen de la idea de Latinoamérica. In: ZEA, Leopoldo (Comp.). Fuentes de la cultura latinoamericana. Tomo I. México: Fondo de Cultura Económica, 1993. p. 461-475.

ROJAS MIX, Miguel. Los cien nombres de América. Barcelona: Editorial Lumen, 1991.

ROUQUIÉ, Alain. O Extremo-Ocidente: introdução à América Latina. São Paulo: EDUSP, 1991.

SCHEIDT, Eduardo. Representações de América no pensamento de Francisco Bilbao. Dimensóes. Vitória: NPIH/Ufes, n. 19, 2007. p. 27-47.

SORIA, Esther Aillón. La política cultural de Francia en la génesis y difusión del concepto L'Amerique Latine, 1860-1930. In: GRANADOS GARCIA, Aimer y MARICHAL, Carlos (Comp.). Construcción de las identidades latinoamericanas. Ensayos de historia intelectual, siglos XIX y XX. México: El Colegio de México, 2004. p. 71-105.

ZEA, Leopoldo (Comp.). Fuentes de la cultura latinoamericana. Tomo I. México: Fondo de Cultura Económica, 1995. 